\title{
PYROMETRY APPLIED TO THE HARDENING OF HIGH-SPEED STEELS.
}

The first part of the evening session, which resumed at 8.30 p.m., was devoted to the consideration of a group of papers and communications dealing with the application of pyrometry to metallurgy, and particularly the metallurgy of steel.

Professor J. O. Arnold, F.R.s. (University of Sheffield), spoke on "Pyrometry Applied to the Hardening of High-speed Steels."

The subject I have to speak about is the hardening of high-speed steel. I hope you have formed no hopes that I am going to enter into a discussion of high-speed steel. It is a very ticklish subject. I have only tried it once in London, and it was more than my life was worth. At the same time, one can deal with advantage with the hardening, pyrometrically controlled, of high-speed steel. It is a matter of general knowledge that steel metallurgists have come almost unanimously to the conclusion that the most usual and the best average temperature to harden high-speed steel is $\mathrm{I}, 300^{\circ} \mathrm{C}$, and I want to lay before you to-night some of the actual results we have obtained at Sheffield University on this basis.

In my opinion there is nothing that secures regularity of temperature so efficiently for this purpose as the salt bath. All high-speed steels are generally hardened through a bath of barium chloride, melted by two iron electrodes to a state of fluidity, and by adjustment the current is kept to a point which enables a temperature of $1,300^{\circ}$ to be maintained, or very nearly so. The tools to be hardened are immersed in this bath, and then they are quenched in various ways-in air, in an air blast, in oil, and in water. We have made several researches on this matter at the University which have not hitherto been published, and some of the data which I am at liberty to publish I think may prove interesting.

First of all, I will explain a simultaneous set of experiments taken with five different pyrometers. The pyrometers we have used are, first, the léry. This is a thermoelectric pyrometer, in which the heat-rays are focused on to a small thermocouple which gives a high e.m.f. over a small increase in temperature. This is measured in terms of current by means of a D'Arsonval galvanometer. The galvanometer registers temperatures from $900^{\circ}$ to $2,000^{\circ} \mathrm{C}$. Readings are taken with one-fifth of full aperture of the telescope opening. It is essential that the galvanometer be kept at a low constant temperature.

The second type of pyrometer is also a Féry, but is a less delicate instrument with a spiral spring. The heat-rays are focused on to a small bimetallic spiral, the movements of which under the influence of heat are greatly magnified by means of a light aluminium pointer. This pointer moves over an arc graduated in degrees of temperature up to $1,700^{\circ} \mathrm{C}$. In use, these 


\section{PYROMETRY APPLIED TO THE HARDENING OF}

instruments should be allowed to attain "room temperature," the indicator then being set at zero. After opening the aperture, the first stop of the indicator is the desired temperature reading, as the temperature of the surrounding atmosphere will in a short time give an increased reading.

The third type we used, the Foster base-metal thermocouple, is of course more or less based on the Le Chatelier pyrometer, in connection with which, by the way, we ought to recognize Professor Tait as the pioneer of this type. The working temperature of this pyrometer is a maximum of $\mathrm{I}, 35^{\circ} \mathrm{C}$. The couple is nickel-chrome alloy against nickel or against a different nickel-chrome alloy. The e.m.f. generated at a given temperature is, however, much greater than is the case with the platinum series of couples, so that a much more robust galvanometer of the low-resistance type may be used. The stem of the couple, except the twisted end, is protected by a refractory covering, and provided that only the twisted end is heated to the temperature to be measured, very reliable readings may be obtained. The mass of the couple is comparatively large, and should that portion from the couple to the leads be heated, there ma be low readings due to loss of heat by conduction. The galvanometer is furnished with a ready means of adjusting to room temperature, so that no corrections for cold-junction effect are necessary. Temperatures for reliable readings are from $500^{\circ}$ to $\mathrm{I}, 400^{\circ} \mathrm{C}$.

The fourth type of pyrometer was the Leskole optical or modified Wanner. In this, by means of an optical system enclosed in a telescope, light rays of different wave-length are selected from the source whose temperature is to be measured, and also from a standard electric lamp illuminated by means of a 4-volt accumulator. It is so arranged that light from the source and that from the stanclard are polarized in planes at right angles to each other, so that on rotating the analyser it is possible to enhance the brightness of one-half the field and diminish that of the other, and so bring each half ficld to a!l exact match in red tint. The position of the analyser, as indicated by a pointer, gives on reference to a table the desired temperature. Periodically the electric lamp is checked against an amyl acetate flame of definite dimensions.

The fifth type was the Mesure and Nouel, for which I have a very great affection. Its one fault is that the results depend so very largely upon the personal equation. If you can obtain an observer who has got into the way of making accurate results, properly used I regard that as one of the most accurate pyrometers we have. In it, the light rays from the heated body are plane polarized by passing first through a Nicol prism, then a quartz plate of definite thickness, and finally a Nicol prism which acts as analyser. The quartz plate rotates the plane of polarization of each coloured ray to an amount depending on its wave-length and at the same time absorbs the yellow rays. On rotating the analyser the colour seen passes at once from red to green, and between these is the sensitive tint, the position of which indicates the temperature by means of angle of rotation, which is then referred to a table.

Our system in this research is this: we select our best senior undergraduates. Each man has a different instrument, and the readings are taken simultaneously from the barium chloride bath, neither man having any idea of what the other is getting, and I was very much astonished to find the splendid results we got from all these pyrometers. It at once occurred to my mind that, properly used, whatevèr type of pyrometer was employed was reliable, and a great debt by metallurgists is due to the physicists to whom these instruments are due. Where bad results have been obtained, 
HIGH-SPEED STEELS : PROFESSOR J. O. ARNOLD 273

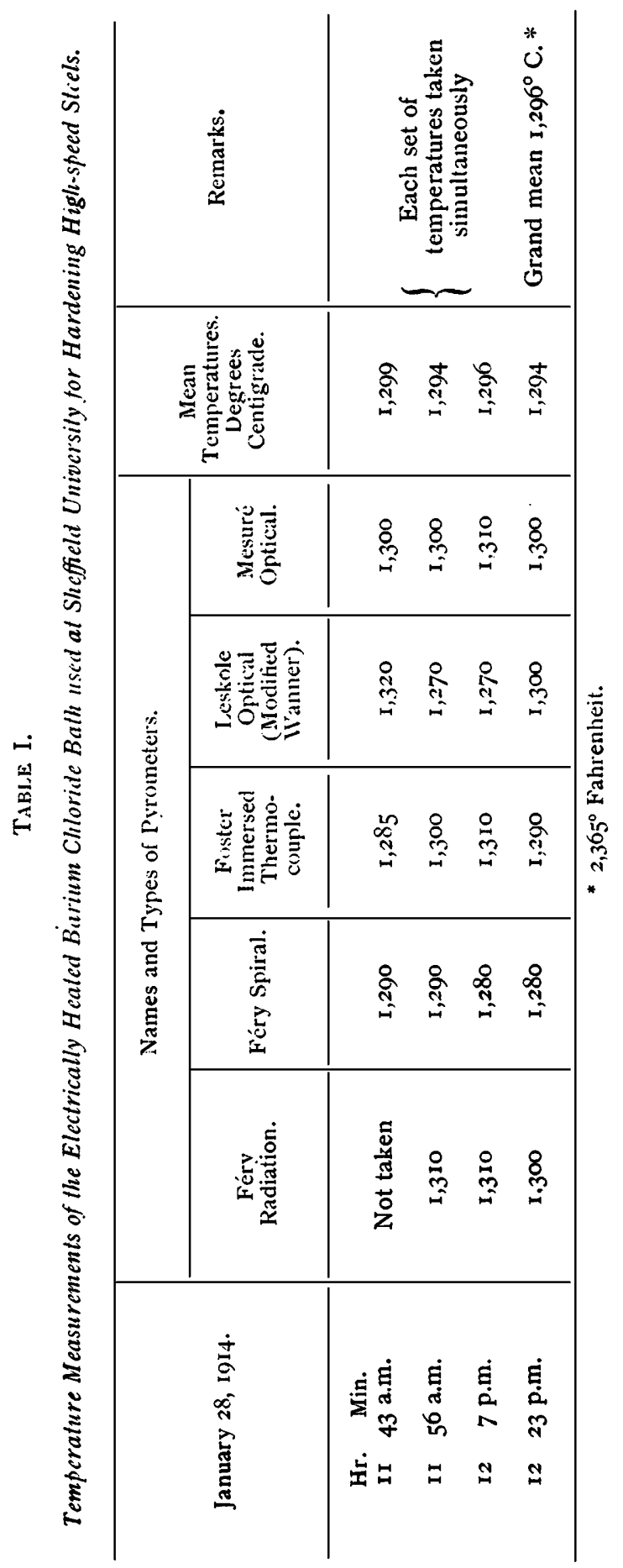


I think it is very largely due to lack of skill of the operator. We were aiming at a mean temperature for hardening of $\mathrm{I}, 300^{\circ} \mathrm{C}$. before quenching. The grand mean of this large series is $1,296^{\circ} \mathrm{C}$., which is a pretty good result (see Table I). If you go through all the figures you will find that the differences in every case are such as might be due to slight variations in the instrument, but more, I think, to the personal equation and the observer. I may say that I know what is coming up later-that hardening high-speed steel with the barium chloride bath secures blackbody conditions throughout, and that may have something to do with the remarkable agreement of all the results with five different pyrometers. The Féry spiral does not pretend to be anything more than a rapid rcugh approximation. So much for the first table. In the second table, we have

TABLE II.

\begin{tabular}{|c|c|c|c|c|c|c|}
\hline \multirow{2}{*}{\multicolumn{2}{|c|}{$\begin{array}{l}\text { June } 16, \\
\text { I914. }\end{array}$}} & \multicolumn{3}{|c|}{ Names and Types of Pyrometers. } & \multirow{2}{*}{\begin{tabular}{|c|} 
Mean \\
Tempera- \\
tures. \\
Degrees \\
Centigrade.
\end{tabular}} & \multirow{2}{*}{ Remarks. } \\
\hline & & $\begin{array}{l}\text { Mesuré } \\
\text { Uptical. }\end{array}$ & $\begin{array}{l}\text { Leskole } \\
\text { Optical. }\end{array}$ & $\begin{array}{l}\text { Foster } \\
\text { Immersed } \\
\text { Thermo- } \\
\text { couple. }\end{array}$ & & \\
\hline & Min. & & & & & \multirow{15}{*}{$\begin{array}{l}\text { Grand } \\
\text { mean }\end{array}$} \\
\hline & 40 a.m. & I,3 Io & 1,220 & I,3 IO & $I, 280$ & \\
\hline & 45 a.m. & 1,300 & 1,300 & 1,300 & $\mathrm{I}, 300$ & \\
\hline ro & 55 a.m. & 1,300 & $\mathrm{r}, 230$ & $\mathrm{I}, \mathbf{2 8 0} \mathrm{O}$ & 1,270 & \\
\hline II & 5 a.m. & $\mathrm{I}, 280$ & I,246 & 1,270 & $\mathrm{I}, 264$ & \\
\hline II & I5 a.m. & 1,300 & I, 280 & 1,300 & I,294 & \\
\hline II & 23 a.m. & $\mathrm{I}, 3 \mathrm{CO}$ & $\mathrm{I}, 295$ & 1,300 & 1,298 & \\
\hline I I & $3^{6}$ a.m. & 1,300 & 1,290 & 1,3 IO & 1,300 & \\
\hline iI & 40 a.m. & 1,330 & I.320 & $1,33^{\circ}$ & 1.327 & \\
\hline II & 44 a.m. & 1,325 & Not taken & I, 310 & 1,317 & \\
\hline II & 46 a.m. & 1,310 & ditto & Couple broken & I,3 IO & \\
\hline II & 55 a.m. & 1,300 & ditto & ditto & $\mathrm{r}, 300$ & \\
\hline 12 & 4 p.m. & 1,300 & 1,300 & $\mathrm{I}, 320$ & $\mathrm{I}, 307$ & \\
\hline 12 & I2 p.m. & I,300 & I,310 & $\mathrm{I}, 33^{0}$ & $\mathrm{I}, 3 \mathrm{I} 3$ & \\
\hline 12 & I9 p.m. & Not taken & Not taken & Not taken & - & \\
\hline
\end{tabular}

three photometers, but with a large number of observations, and here we get bigger variations. As you will see, the grand mean is 1,305 , and we were aiming at $I, 300$. I have a great faith in observations like these in taking the grand mean. There again you will see, taken as a whole, the Mesuré and Nouel gives a very good constant, but the variations in this set of observations are considerably greater than in the first series, showing the influence of the personal equation. So much for high-speed steel.

At the present time, I am sure my friend Mr. Cosmo Johns will admit that it is very important that we should get a constant record of the temperature of steel tapped from the open-hearth furnace, and that is a very difficult matter, particularly in a large furnace. Therefore, I thought it might be well to include a few results obtained from our small 2-ton Siemens furnace in the Sheffield University. One is particularly interesting. The first series are temperatures taken in I9I0 with the old original Wanner. In putting 
in a Siemens furnace, it is usual to charge it with what is called a pig melt, to consolidate the bottom after repairing it, when you are starting from cold ; and this in our small furnace has reference to a pig melt of hematite iron of only half a ton, which we melted to a bright heat and cast into a ladle, and then allowed to cool somewhat, because we were going to utilize this melt to make iron for casting floor-plates for the furnace. I got some good students, and we cast five plates weighing $\mathrm{I}_{2} \frac{1}{2} \mathrm{cwt}$. each, and we took very carefully the casting temperature of each plate. It was in a small ladle, and it was a small charge even for a small ladle, so radiation would be pretty rapid. The casting temperature of the first plate was registered at $\mathrm{I}, 300^{\circ} \mathrm{C}$. ; the second was $\mathrm{I}, 28 \mathrm{o}$, the third $\mathrm{I}, 243$, the fourth $\mathrm{I}, 258$, and the fifth $\mathrm{I}, 208$. That means that the average fall of temperature during the casting operation per plate was $18^{\circ} \mathrm{C}$.

I have also selected a series of experiments carried out at a later date, in which two undergraduates were working with a Leskole and a Mesuré and Nouel pyrometer. The mean of their readings was taken and put down on the board. That was in December, ror4, and the casting temperatures of the pig melt were very high, $\mathrm{I}, 525^{\circ} \mathrm{C}$. Of course, that is quite possible, but I rather doubt that reading; it was recorded as the mean of the two pyrometers. We cast five heats of structural steel, mean carbon about $0 * 35$. The tapping temperature of the first heat was 1,600 , the second I,550, the third 1,630 , the fourth 1,570 , and the fifth 1,620 . In our next run, in March, 1915, the pig melt casting temperature registered was 1,440, which $I$ think is pretty near the average mark, and the heats were I 625, $\mathbf{I}, 600,1,600,1,600,1,590$, and 1,600 . I think the evenness of some of these results is too good to be true literally, but still I do not think they are very far off.

These are a few of the records taken at random from our long experience with the use of pyrometers in hardening high-speed steel and casting, and $I$ hope they will form the basis for a valuable discussion. 